\title{
Map of the Village of Koto
}

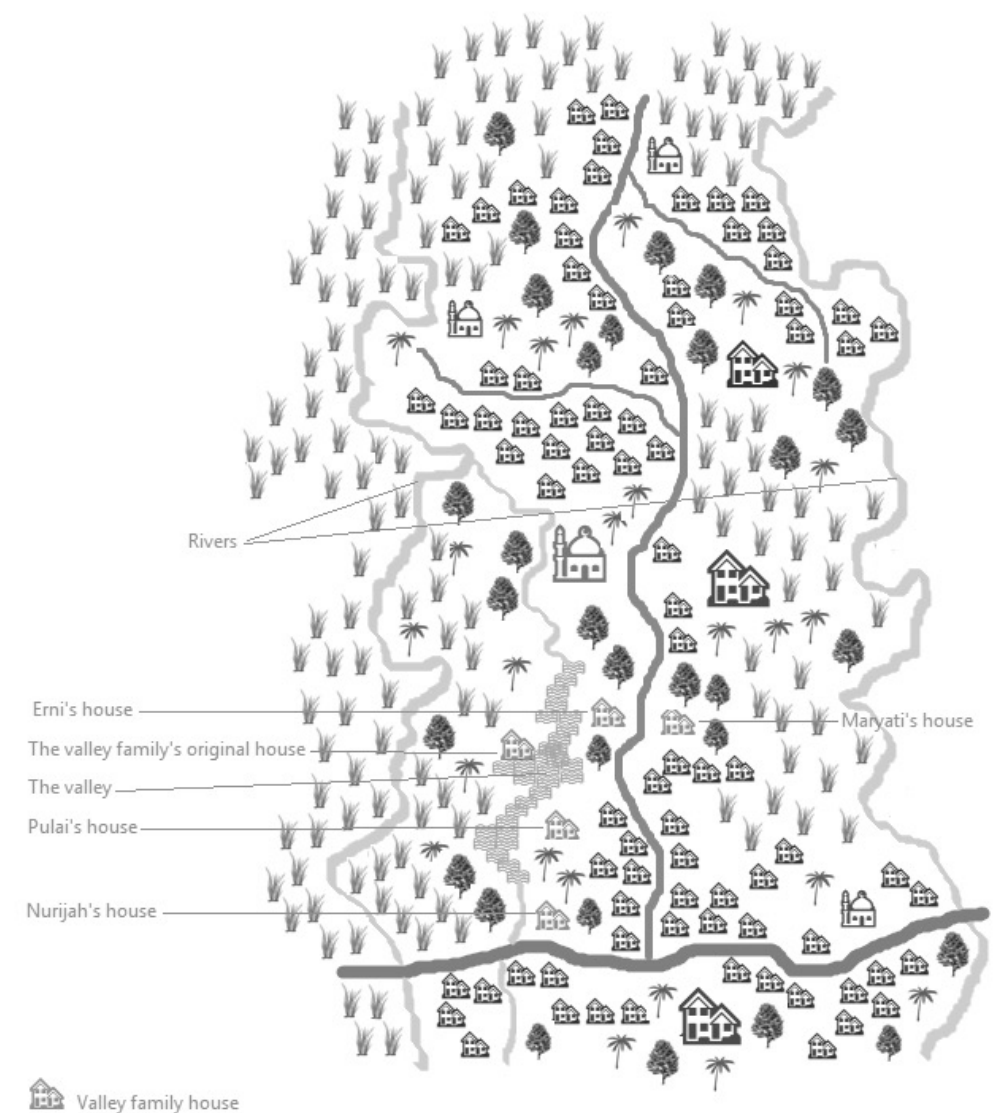

进它 Valley family house

Residential area

会會 Primary school

菙率

Kindergarter

Aी Mosque

Â Surau (prayer house)

\section{The Village of Koto}

Residential areas concentrate around the village roads and the intersection with the main road. Rice fields and other productive land surround the clusters of houses. 